Proceedings

\title{
Towards the Development of a Smart Plant Protection Solution for Improved Pest Management of Dry Beans (Phaseolus vulgaris L.) in Northern Greece ${ }^{\dagger}$
}

\author{
Petros Damos ${ }^{1, *}$, Evaggelos Tsikos ${ }^{1}$, Malamati Louta ${ }^{2}$ and Fokion Papathanasiou ${ }^{1, *}$ \\ 1 Department of Agriculture, School of Agricultural Sciences, University of Western Macedonia, Greece; pe- \\ trosdamos@gmail.com, etsikos89@gmail.com,fpapathanasiou@uowm.gr, \\ 2 Department of Electrical and Computer Engineering, Telecommunication Networks and Advanced Services \\ Laboratory, University of Western Macedonia, Greece; louta@uowm.gr \\ * Correspondence: fpapathanasiou@uowm.gr; \\ + Presented at the 1st International Electronic Conference on Entomology (IECE 2021), 1-15 July 2021; \\ Available online: https://iece.sciforum.net/.
}

Citation: Damos, P.; Tsikos, E.; Louta, M., Papathanasiou, F. Towards the development of a smart plant protection solution for improved pest management of dry beans (Phaseolus vulgaris L.) in Northern Greece Proceedings 2021, 68, x. https://doi.org/10.3390/xxxxx

Published: 2 July 2021

Publisher's Note: MDPI stays neutral with regard to jurisdictional claims in published maps and institutional affiliations.

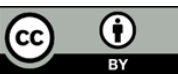

Copyright: (c) 2021 by the authors. Submitted for possible open access publication under the terms and conditions of the Creative Commons Attribution (CC BY) license (http://creativecommons.org/licenses/by/4.0/).

\begin{abstract}
In the present work we present the initial stages and first results of the development of a site-specific intelligent plant protection system for bean cultivation. The aim of the system is to be used as a decision tool for rational management of the major key pests of bean crop and with the view to reduce plant protection costs and to mitigate side effects and negative impact on the environment. Currently, we have established a telemetric meteorological network which consists of seven meteorological stations which are distributed in the major bean cultivation area of Greece and over the border area of the Prespes National Park. Through climate sensors the network delivers real time weather data to a cloud server to be further used to establish real time risk thresholds of pest occurrence during the bean growth season. Additionally, the system is passing a stage of pest models development and risk thresholds using in field phenology data along with weather data and Growing Degree-days. Particularly, for the development and validation of the pest risk thresholds we have established experimental fields. The risk thresholds include the pests: Helicoverpa armigera, Thrips sp. and Tetranychus urticae. Pest phenology is observed in four experimental fields which consist of two conventional as well as two organic fields serving as control. The current results will contribute to a better exploitation of the established meteorological station network and their real time microclimate data to provide important information on the rational use of pesticides.
\end{abstract}

Keywords: plan protection; phenology; decision tool; integrated pest management

\section{Introduction}

Given the new Community Directive 2009/128/EC of the European Parliament, which for the first time adopts at Community level a legal framework concerning the rational use of pesticides and management of energy inputs to Agro-ecosystems, there is an urgent need for implementing and improving Integrated Pest Management systems (IPM). IPM combines information of the pest, host plant and microenvironment, to reach a long-term sustainable pest control based on multiple plant protection tactics. However, as a total farm system approach, IPM depends strongly on the delivery of accurate and real time information to mitigate pest pressure and improve crop production [1, 2].

In particular, controlling agricultural pests requires accurate and site-specific climate and pest population thresholds data, delivered in near-real time to the farmer's desk to be used for decision making and rational use of pesticides [3, 4]. In order to be effective timely treatments with pesticides must be applied during the period of high pest activity. 
To date, this is particularly important for bio-rational compounds, such as biological control agents and insect growth regulators, because they are effective against particular stages of pest development [5]. Therefore, there is a need to forecast the population emergence and succession of pest generations in the crop field.

Hence, several weather driven phenological models and related action thresholds, have been developed to estimate the time where pest population occurrence is more likely to appear $[6,7,8]$. Nevertheless, less emphasis is given on the development of automated decision support systems (DSS) to be used on a regular basis for plant protection decision making and the initiation of pest control actions by growers.

Common bean production, $P$. vulgaris is one of the most important crop of the prefectures of Florina and Kastoria in Northern Greece [9]. The Prespa Lakes area particularly, has a long-term established tradition of dry bean cultivation in which the distinct microenvironmental conditions combined with the extensive genetic diversity have led to region-specific high-quality product $[9,10]$. Nevertheless, due to favorable microenvironmental conditions bean cultivation in Northern Greece suffers from the regular presence of arthropods pests including; the cotton bollworm, Helicoverpa armigera, Thrips species, such as Frankliniella occidentalis and Thrips tabaci, as well as the two spotted mites Tetranychus urticae [11]. To protect crop losses, the control of these pests is based on pesticide treatments, which are mostly applied on calendar basis and are often not necessary nor effective since climate conditions are not suitable for pest emergence. As a result, there is an unnecessary contamination of soil, water and other vegetation, as well as further negative impacts on non-targeted species, farmers and the consumers.

The objective of the current project is the development of a DSS and a related wireless smart plant protection solution that can be used by farmers and agricultural advisors, as a smart plant protection solution for improved pest management of dry beans. Farmers could profit by the use of an application which provides close to real time forecasts of pest occurrences as well as related weather information and decision to take on specific actions.

\section{Materials and Methods}

\subsection{Study site and experimental farms}

We are using four experimental bean farms, $0.4-07 \mathrm{ha}$, to run the pest population forecasts and to validate later their prediction performances. Two of the farms are being conventional and receiving the region-specific pesticide treatments according to regular calendar-based pesticides schedule. The two other experimental farms consist of organic bean cultivation which in the past and the current years have not received any conventional pesticides application and serve as control.

\subsection{Pest population monitoring}

We are conducting indirect and direct population monitoring based on the observation of pests captured on traps as well as on the presents of immature stages on plants and related plant damage. Monitoring of $\mathrm{H}$. armigera moths is done with pheromone traps and for Thrips species with sticky traps. We have placed two traps for each species per experimental farm. Observations are carried out two times per week starting from mid to late April and all captured individuals are removed after each observation. To detect the period of the emergence of the immature stages of $\mathrm{H}$. armigera as well the appearance of T. urticae we are performing direct measures-observations of infested plants. Briefly, 1015 bean plants/experimental farm are randomly selected and 15 leaves/bean plant are inspected for the presence of $\mathrm{H}$. armigera immature stages and damage caused by $\mathrm{T}$. urticae. Specifically, for T. urticae we are using damage identification keys and NDVI image processing to rank the percentage of leaf damage caused by the two-spot mite. Observations are carried out twice each week starting one week after bean-plant germination.

\subsection{Meteorological network, whether data and software}


In order to have real time whether data to be further used for the DSS and as inputs for pest population forecasting and the initiation of risk action thresholds, we have established 7 meteorological stations which collect real time data. Currently we work our meteorological network that collects data with a default data sensed software. The data include, among other, air and soil temperature, air and soil moisture, relative humidity and leaf wetness. Data are delivered to cloud server using the Adcon $\circledast$ telemetry software. The software works in a cloud environment, collecting data and exploits large data sets on a remote server to be used later on as inputs for generating pest risk thresholds and some default plant disease models.

To generate real time pest risk alerts the software has to be first parameterized by the user on a GUI environment to generate then real time forecasts. However, if the parameters are not known a priori, or may even be region/species specific, they have to be estimated first and/or calibrated with phenological field trials. The pest threshold forecast are based on heat summation assumptions and related degree-days to complete a particular developmental stage.

\section{Results}

\subsection{Study site and phenological network}

Figure 1 illustrates the particular location where the study is performed as well as the experimental bean farms and the site-specific placement of the pest population observation network (i.e., traps). The overall region for which the DSS is developed and validated, covers an area of approximately 10 square kilometers but could potentially be increased. The main area is situated in the borders of the Prespa Lakes, which is located in Western Macedonia in Northern Greece.

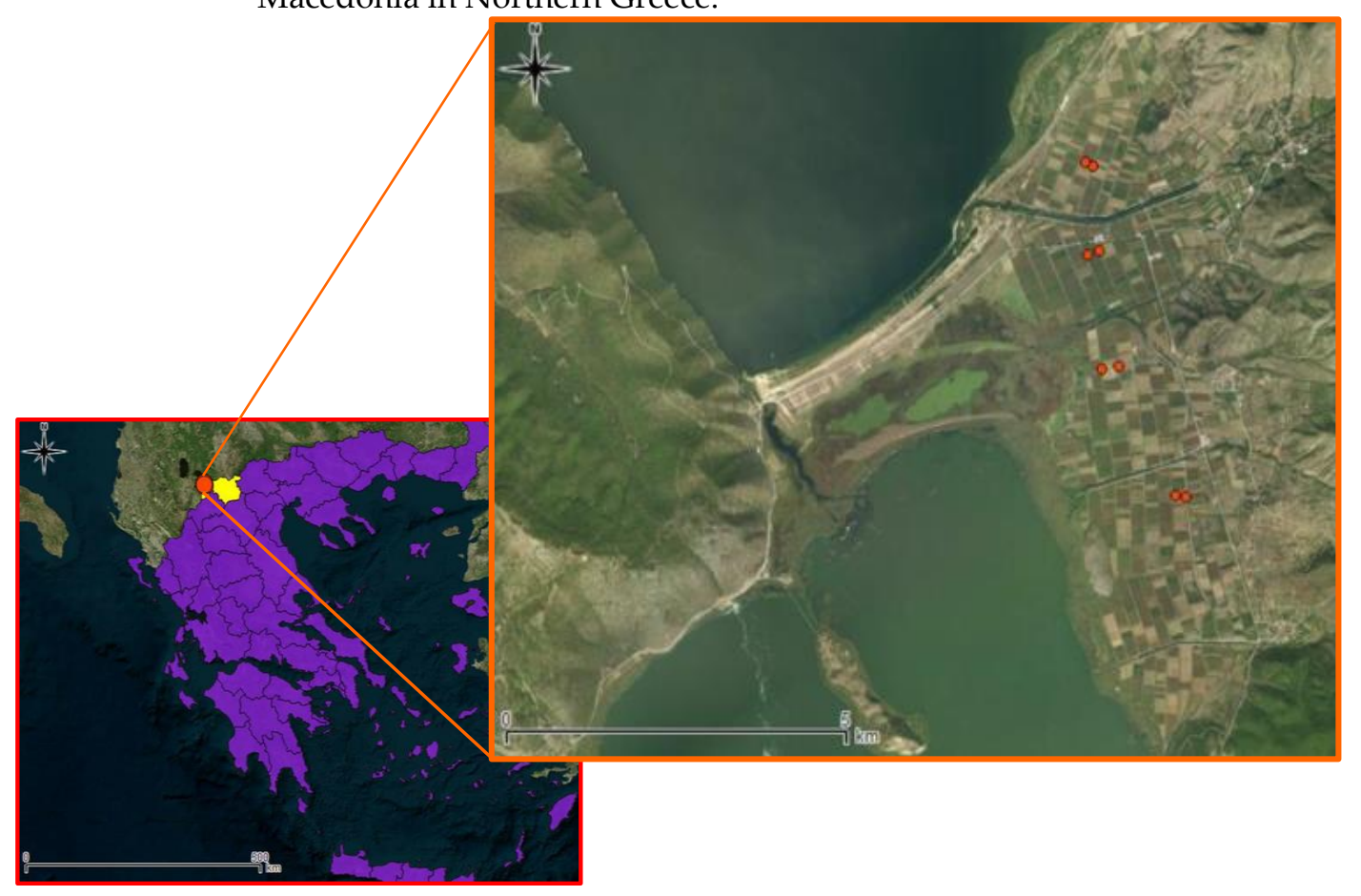

Figure 1. The particular location where the study was performed in the prefecture of Florina in Northern Greece. Points correspond to the trap network established to observe the phenology of H. armigera.

\subsection{Whether data recording and interface of the of the DSS}

Figure 2 illustrates one of the meteorological weather stations that were installed in the bean cultivation area of interest over the Prespa lakes in the prefecture of Florina (a) and the respective temperature recording (b). We have set as Biofix for heat recoding and related degree-days heat summation (are not shown) $1^{\text {st }}$ of January. Note that temperature recordings which are higher than $10,1^{\circ} \mathrm{C}$, which is the lower developmental threshold of 
H. armigera have been mostly recorded after the end of March. Figure 3 shows a second weather station (a) and the temporal evolution of the relative humidity levels as recorded

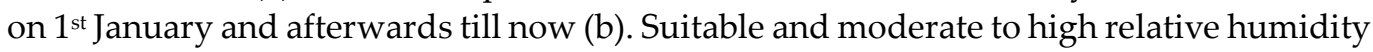
levels are considered important for $H$. armigera egg hatch and development as well as for predatory mites, whilst $T$. urticae growth is mostly favored by dry conditions. Hence the information delivered by the meteorological network so far is essential for indicating the time periods which are suitable for their growth.

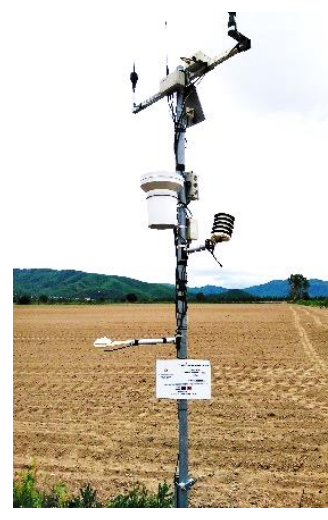

(a)

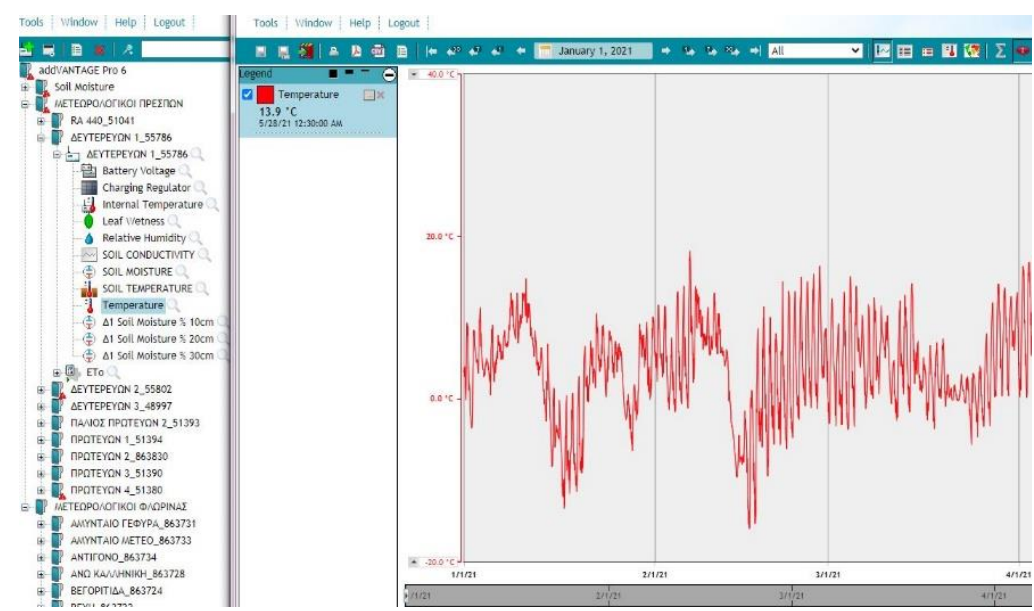

(b)

Figure 2. Daily real time temperature recording in one of the meteorological stations that have been placed in the Prespa Lakes area in the prefecture of Florina in Northern Greece. Left bar indicates the meteorological station as well as the other options available for the user.

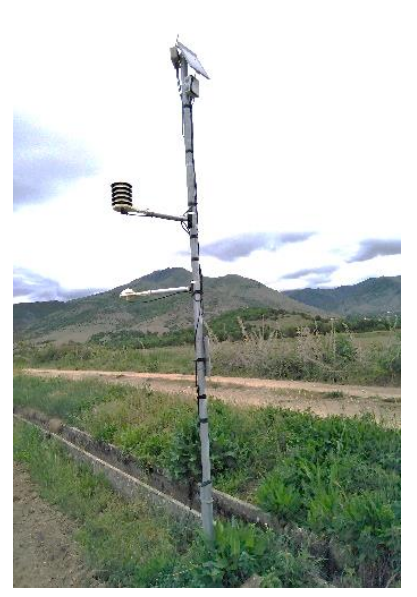

(a)

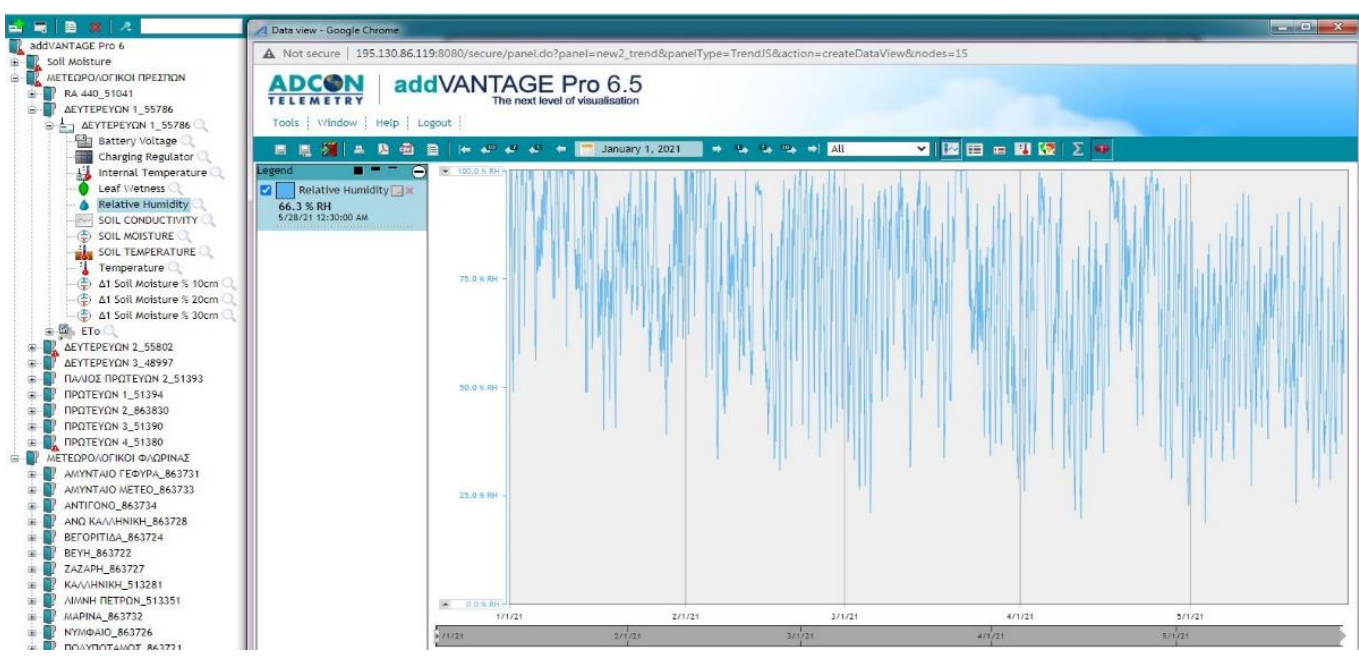

(b)

Figure 3. Daily real time relative humidity levels (\%) recorded in one of the meteorological stations that have been placed in the Prespa Lakes area in the prefecture of Florina in Northern Greece. Left bar indicates the meteorological station as well as the other options available for the user.

\subsection{Degree-days and phenological data of H. armigera}

Here, we present the results for estimating region specific forecasts and validations of the first flight of $H$. armigera moth emergence and population peak. Figure 4 a shows the overall phenology of $H$. armigera moths recorded so far in the four experimental fields in the area of the Prespa Lakes in Northern Greece. The first captures of adult moths were observed on $3^{\text {th }}$ of May and the population continued to increase the following days. The 
population of the first flight peaked during the second week of May and male moth captures were observed till the end of May. However, overall, the captures so far are at low levels and only few individuals have been captured so far. Nevertheless, the species completes usually three to four generations, depending on the region, annually and thus we expect to observe higher populations during the growing season as well as the larvae of the first generation which damage the bean plants and fresh crops during their development. Figure $4 \mathrm{~b}$ shows the predicted degree days for the peak of the first flight of $H$. armigera, according to published estimates from trials performed in the past in Northern Greece [6, 12], along with current observations that correspond to the period were male captures were higher. To date, the accumulated degree-days were calculated using the simple average method [8], with a lower developmental threshold of $10,1^{\circ} \mathrm{C}$ and an upper temperature cut off: $36,5^{\circ}[12]$.

Based on the current preliminary results, there is a difference of 30 degree-days between the observed and predicted moth captures and these values correspond to a time period of approximately 3-4 days. These data will be later compared and calibrated with degree-days threshold prediction of published works and will serve to set up the final region-specific pest population thresholds of the DSS and related smart application. Additionally, we are performing a series of degree-days heat summations and phenological observation to estimate the degree-days needed to occur certain developmental events of other bean key pests in the field including Thrips species and T. urticae. Since these analyses are in progress the results for these pests are not presented.

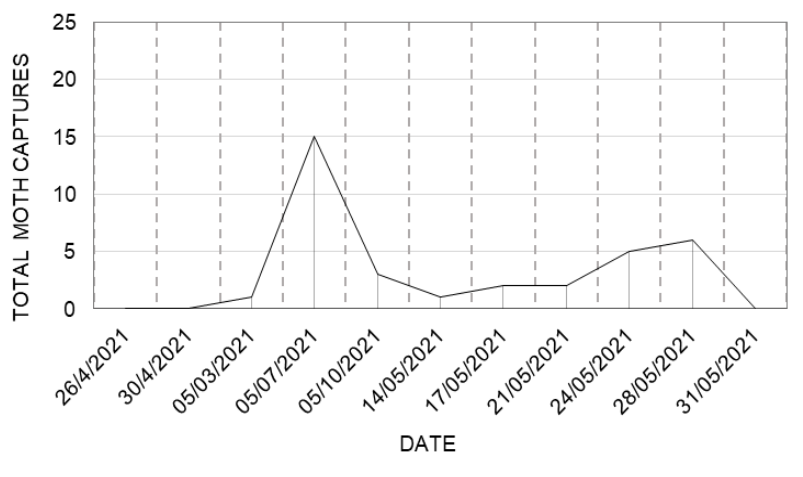

(a)

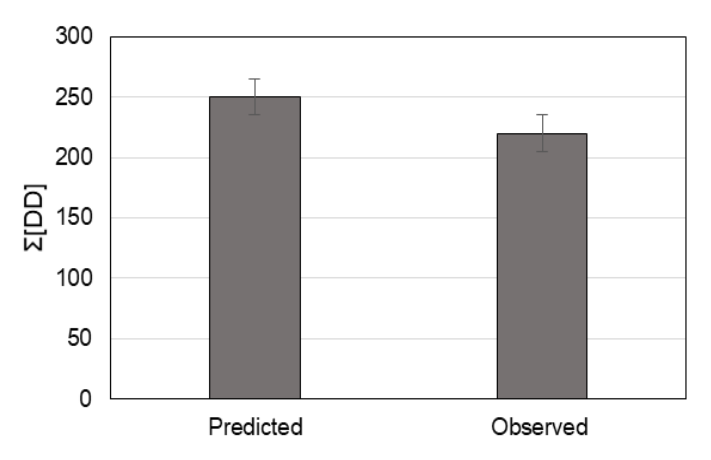

(b)

Figure 4. Total moth captures of H. armigera as observed by pheromone traps in the Prespa Lakes area in the prefecture of Figure 10. C lower developmental threshold and $36,5^{\circ}$ upper temperature cut off.

\section{Conclusion}

The Prefecture of Florina is a region of western Macedonia in Northern Greece which is characterized by very suitable climate conditions for the cultivation of a high-quality bean crop. As a result, bean cultivation has intensified in recent years to meet the growing demand. This fact, in combination with the favourable conditions for pest growth, has led to the emergence of seasonal population outbreaks and an increased use of control measures and insecticides particularly. However, when it comes to translate IPM in praxis it is primarily based on pest field monitoring and relative thresholds establishment, in which mostly pesticides are used at a need basis if alternatives are either non available or non-efficient.

Nevertheless, since IPM emphasizes on timely decision making, knowledge and information which are delivered in real time and in a scientific sound manner, is a prerequisite for successive pest management $[1,2]$. The particular project emphasized on the delivery of timely decision making support system to provide timely regions specific pest risk information to be implemented by bean farmers in one of the most important production area in Greece. 
Conceptually, the crucial part of the proposed DSS, as well as for any DSS, is interoperability between agro-mathematical algorithms that collect site specific weather data from automated weather stations to be used along with pest population models and thresholds to provide real time forecasts [4]. Since the current research work is in progress, we expect to improve decision, after careful assessment of the other bean pests and which are not presented here (i.e. Thrips species and T. urtciae), to include timely and pest specific risk alerts as well as information for the selection of appropriate control options for each case.

From a practical standpoint, we expect that the particular DSS will timely advise growers to take control actions, such as either apply or not pesticides and/or perform specific cultivation practices, to mitigate the impact caused by pests and improve bean quality. The proposed DSS, although in phase of development and validation is combining the inherent strengths of pest phenology modeling and information technology to deliver at the end-user information concerning the time periods where the pest risk is higher and related actions should be performed. Therefore, the current work, although preliminary, is considered essential for the development of an automated decision-making tool helping plant protection managers to make better decisions and improve yield and qualitative characteristics of the final bean dry product.

Author Contributions: “Conceptualization, F.P., P.D. and M.L.; methodology, data curation and formal analysis, P.D.; experimental set up, field trials and data collection, E.T and F.P.; writingoriginal draft preparation, P.D.; writing - review and editing F.P and M.L.; project administration F.P and M.L. All authors have read and agreed to the published version of the manuscript.

Funding: “This research was funded by a research grant (number: MIS 5047196), being part of the research program“New Technologies and Innovative Approaches to Agri-Food and Tourism to Boost Regional Excellence in Western Macedonia (AGRO-TOUR)" and the action "Smart bean cultivation optimization system in the context of precision agriculture".

Conflicts of Interest: “The authors declare no conflict of interest and the grand funders had no role in the design of the study; in the collection, analyses, or interpretation of data; in the writing of the manuscript, or in the decision to publish the results".

\section{References}

1. Bajwa, W. I; Kogan, M. Database Management System for Internet IPM Information. (2003) pp. 216-220

2. Bajwa, W.I.; Coop, L.; Kogan, M. (2003) Pest management (IPM) and Internet-based information delivery systems. Neotropical Entomology (2000), 32:373-383.

3. Singh, N.; Gupta, N. ICT based decision support systems for Integrated Pest Management (IPM) in India: A review. Agricultural Reviews, (2016), 37, 309-316.

4. Damos, P. Modular structure of web-based decision support systems for integrated pest management. A review. Agron. Sustain. Dev. (2015), 35, 1347-1372.

5. Horowitz, A.R.; Ishaaya I. Biorational Insecticides - Mechanisms, Selectivity and Importance in Pest Management Programs. In: Insect Pest Management- Field and Protected Crops (A. R. Horowitz and I. Ishaaya, eds.), (2004) pp.1-28. Springer, Berlin, Heidelberg, New York.

6. Dalal, P.K.; Arora, R. Model-based phenology prediction of Helicoverpa armigera (Hübner) (Noctuidae: Lepidoptera) on tomato crop. J Plant Dis Prot (2019), 126, 281-291.

7. Bartekova, A.; Praslicka, J. The effect of ambient temperature on development of cotton bollworm (Helicoverpa armigera Hübner, 1808). Plant Prot Sci (2006), 42:135-138.

8. Damos, P.; Savopoulou-Soultani. Temperature-Driven Models for Insect Development and Vital Thermal Requirements. PsycheVolume 2012, (2012) Article ID 123405,13pagesdoi:10.1155/2012/123405

9. Papadopoulos, I.; Papathanasiou, F.; Vakali, C.; Kazoglou, I.; Tamoutsidis, E.Local landraces of dry beans (Phaseolus vulgaris L.): a valuable resource for organic production in Greece. Acta Horticulturae (2012) 933, 75-81.

10. Papathanasiou, F.; Barbayiorgis, A.; Papadopoulou, V.; Kareklas, E.; Galaitsis, D.; Papadopoulou, F; Tamoutsidis, E; Papadopoulos I. (2014). Physiological performance and yield of dry bean (Phaseolus vulgaris L.) genotypes under water deficit. Book of Abstracts of the AgriBalkan-Balkan Agricultural Congress, Edirne, Turkey, 8-11 September 2014, pp 398.

11. Duff, J. Integrated pest management in the green bean industry. Project Number: VG02030. ISBN 0734114621 Published and distributed by: Horticultural Australia Ltd. Available at: https://ausveg.com.au/app/data/technical-insights/docs/VG02030_complete.pdf (accessed 18/5/2021) 
12. Damos, P.; Mantzoukas, S.; Theoharis, X., Zaggos, G., Staurakoulis, N., Karanastasi, E., Perdikis D. 2015. Development and first evaluation of seasonal and spatial models of Helicoverpa armigera and Tuta absoluta in industrial tomato cultivations in the prefectures of Ilia and Achaia, $16^{\text {th }}$ PanHellenic conference on Entomology, 20-30 October, Heraklion, Greece (abstract in Greek). 